\title{
DIAGNOSIS: Trans-Scaphoid Perilunate Fracture-Dislocation
}

Trans-scaphoid perilunate fracture-dislocations (TSPLFD) are relatively uncommon but potentially serious wrist injuries. Due to subtle clinical and radiographic findings, approximately $25 \%$ cases are missed at initial admission in emergency departments. ${ }^{[1]}$ In case delayed diagnosis, complex surgical procedures are needed for reconstruction and considerable long term morbidity including radio-carpal arthritis, carpal instability, or median nerve damage may occur. ${ }^{[2]}$ Therefore, it is important to recognize these rare injuries at initial admission to prevent possible loss of wrist function.

Timely identification of these injuries necessitates detailed physical examination, proper radiographic interpretation and high index of suspicion. Clinically, there is usually dinner fork deformity, however, gross swelling may masquerade this typical finding. The range of normal wrist motion is restricted and there may be median nerve compression findings such as hypoesthesia and tingling in the first finger through third. Physical examination findings are often not very specific, and radiographic examination should be performed.

Although standard antero-posterior and lateral wrist radiographs are usually adequate for a correct diagnosis, a systematic evaluation of radiographs is essential. On a normal AP wrist radiograph, there are three imaginary carpal arcs joining the surfaces of the carpal bones, so called the 'Arcs of Gilula' (Figure 2a). Arcs of Gilula show the anatomic alignment of the carpal bones, and extend parallel to each other. ${ }^{[3]}$ Intersection of these lines with each other, and loss of symmetry and parallelism in the joint spaces should alert us for a possible trans-scaphoid perilunate fracture-dislocation (Figure $2 \mathrm{~b}$ ). A lateral wrist radiograph provides more valuable information about the extent of injury. On a normal lateral wrist radiograph, the radius, lunate, capitate and the third metacarpal bone should be on the same line (Figure 3a). In case of transscaphoid perilunate fracture dislocation, this normal alignment is disrupted, and the lunate loses its relation with capitate (Figure $3 \mathrm{~b}$ ). Computerized Tomography (CT), particularly the sagittal reconstruction, clearly delineates this abnormal alignment (Figure $3 c$ ). ${ }^{[4]}$

Emergency physicians should be familiar with the normal and abnormal radiographic anatomy of the wrist in order to reduce the risk of misdiagnosis of this decapacitating injury.

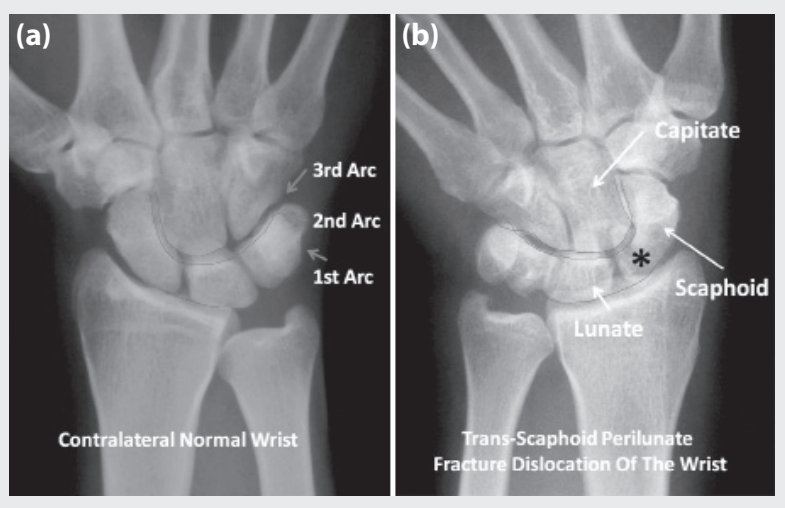

Figure 2. (a) The first arc is a smooth curve outlining the proximal convexities of the scaphoid, lunate and triquetrum. The second arc traces the distal concave surfaces of the same bones, and the third arc follows the main proximal curvatures of the capitate and hamate (red lines) (b) The intersection of arcs of Gilula and scaphoid fracture (black asterix) is seen.

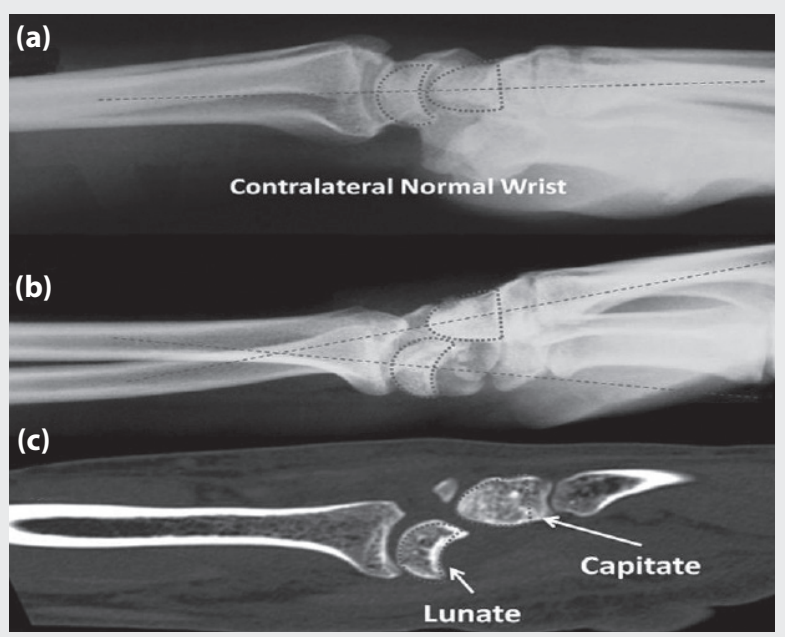

Figure 3. (a) Normal lateral wrist radiograph showing the proper alignment of radius, lunate, capitates and metacarpal shaft. (b) Disruption of the alignment in transscaphoid perilunate fracture-dislocation. (c) The sagittal reconstruction of wrist CT of the patient showing the dorsal dislocation of capitate.

\section{References}

1. Herzberg G, Comtet JJ, Linscheid RL, Amadio PC, Cooney WP, Stalder J. Perilunate dislocations and fracture-dislocations: a multicenter study. J Hand Surg Am 1993;18:768-79. [CrossRef]

2. Komurcu M, Kürklü M, Ozturan KE, Mahirogullari M, Basbozkurt M. Early and delayed treatment of dorsal transscaphoid perilunate fracture-dislocations. J Orthop Trauma 2008;22:535-40.

3. Najarian R, Nourbakhsh A, Capo J, Tan V. Perilunate injuries. Hand (N Y) 2011;6:1-7. [CrossRef]

4. Stanbury SJ, Elfar JC. Perilunate dislocation and perilunate fracture-dislocation. J Am Acad Orthop Surg 2011;19:554-62. 